\begin{tabular}{|l|l|l|l|l|l|}
\hline J. Tek. Ling & Vol. 10 & No. 2 & Hal. 167 - 172 & Jakarta, Mei 2009 & ISSN 1441-318X \\
\hline
\end{tabular}

\title{
KEANEKARAGAMAN JENIS-JENIS ANGGREK KEPULAUAN KARIMUNJAWA
}

\author{
Diah Sulistiarini dan Tutie Djarwaningsih \\ Peneliti di Pusat Penelitian Biologi \\ Lembaga Ilmu Pengetahuan Indonesia
}

\begin{abstract}
Karimunjawa is a group of small islands which is situated at 0 up to 506 above sea levels, and covered of total forests area of about 1,300 ha. The area is located within Jepara Regency, Central Java. Studies on forest ecology and floristic of the island has been conducted in 2003 to 2006. The present study is apart of the floristic studies with special attention to orchids. Based on field study combined with specimen herbarium stored in the Herbarium Bogoriense, there are at list 13 species of orchid collected from Karimunjawa Island, and one of them is recognized as endemic species in Jawa. In addition there is one unidentified species which is belonging to genus Eria.
\end{abstract}

Keywords: Orchids, Karimunjawa Island, Herbarium Bogoriense

\section{PENDAHULUAN}

\subsection{Latar Belakang}

Anggrek termasuk salah satu kelompok tumbuhan kosmopolitan yang hampir tersebar di seluruh bagian dunia. Akan tetapi tipe dan keberadaan suatu vegetasi ada kalanya dapat menjadi faktor pembatas persebaran jenis-jenis anggrek.

Seperti halnya kelompok tumbuhan tinggi lainnya, anggrek lebih banyak tumbuh di daerah tropik dan dengan persebaran yang tidak seragam. Beberapa jenis diketahui mampu tumbuh dan berkembang pada daerah dataran rendah sampai ke daerah dataran tinggi. Dilain pihak ada jenis-jenis lain yang hanya tumbuh dan berkembang pada daerah dengan kisaran ketinggian tertentu ${ }^{1}$. Dilaporkan bahwa keanekaragaman jenis anggrek tertinggi terdapat pada ketinggian $500-2000 \mathrm{~m}$ dpl. ${ }^{2}$. Keberadaan anggrek di Jawa telah dimuat secara lengkap dalam beberapa buku diantaranya Backer \& Bahkuizen ${ }^{3)}$ dan Comber $^{2}$ tetapi tidak dijelaskan secara rinci mengenai lokasi penyebaran dari masing-masing jenis. Selain itu keberadaan anggrek di Jawa khususnya yang terdapat di dalam kawasan konservasi Jawa Barat juga telah diungkapkan Puspitaningtyas, $\mathrm{dkk}^{4}$. Namun demikian keberadaan jenisjenis anggrek di kawasan Karimunjawa sampai saat ini belum terdokumentasi dengan baik.

Kepulauan Karimunjawa merupakan kumpulan pulau-pulau kecil yang terletak pada ketinggian 0 - $506 \mathrm{~m}$ dpl. Daerah ini mencakup areal seluas 1.285,50 ha., yang berupa kawasan hutan hujan tropis dataran rendah.

Menurut klasifikasi iklim Schmidt \& Fergusson ${ }^{5}$ daerah kepulauan Karimunjawa tergolong tipe $C$ dengan rata-rata curah hujan tahunan sebesar $3.000 \mathrm{~mm}$ dan rata-rata curah hujan bulanan selalu $>100 \mathrm{~mm}$. Dengan demikian dapat digolongkan beriklim selalu basah. 
Berdasarkan tipe vegetasinya maka daerah penelitian dapat dikelompokkan kedalam tiga kawasan, yaitu daratan, perairan dan mangrove. Menurut laporan Anonim6) keberadaan flora umum di ketiga kawasan tersebut telah diketahui, tetapi tidak disebutkan adanya anggrek di dalamnya.

\subsection{Tujuan Penelitian}

Tujuan utama penelitian ini adalah untuk mengungkapkan keberadaan jenis anggrek di daerah Karimunjawa. Dengan demikian keberadaan jenis-jenis anggrek di daerah ini dapat terdokumentasi dan dapat menambah informasi keanekaragaman jenis anggrek di Jawa.

\section{METODOLOGI}

Bahan penelitian berupa koleksi tumbuhan anggrek yang berasal dari Kepulauan Karimunjawa hasil eksplorasi yang dilakukan antara tahun 2003 dan 2006 serta koleksi anggrek yang tersimpan di Herbarium Bogoriense. Adapun koleksi dari Kepulauan Karimunjawa berasal dari Legon Lele., Legon Goprak, Legon Moto., Kemloko Nyamplungan, P. Bengkoang, P. Genting, P. Kembar, P. Kumbang, P. Nyamuk,P. Parang, dan $P$. Sambangan yang terletak pada ketinggian 0 - $506 \mathrm{~m}$ dpl.

Metode pengambilan contoh tumbuhan anggrek mengikuti cara Balgooy ${ }^{7}$ yang sudah umum dilakukan untuk koleksi tumbuhan tinggi. Setiap tumbuhan anggrek diambil contohnya untuk dibuat herbarium. Caranya yaitu semua contoh tumbuhan anggrek yang dikumpulkan di lapangan diawetkan dalam alcohol $70 \%$, dimasukkan ke dalam kantong plastik, ditutup rapat, kemudian dikirim ke Herbarium Bogoriense untuk dikeringkan dan disimpan. Specimen tersebut kemudian diidentifikasi berdasarkan spesimen herbarium dan/atau dengan pustaka acuan untuk menentukan jenisnya.

\section{HASIL DAN PEMBAHASAN}

Dari hasil eksplorasi telah berhasil dikumpulkan 13 jenis anggrek (Tabel 1). Dari 13 jenis tersebut 1 jenis diantaranya yaitu Eria bogoriensis merupakan anggrek endemik di Jawa.

Keanekaragaman jenis anggrek di Kepulauan Karimunjawa termasuk rendah dibandingkan dengan Pulau Wawonii yang luasnya hanya sekitar $650 \mathrm{~km}^{2}$, tetapi tercacah sebanyak 91 jenis anggrek dan 36 jenis diantaranya merupakan rekor baru $^{10)}$.

Berdasarkan perawakannya anggrek dapat dikelompokkan menjadi dua kelompok yaitu anggrek tanah dan anggrek epifit. Dari 13 jenis yang tercatat, 5 jenis diantaranya termasuk anggrek tanah yang terdiri atas jenis-jenis Eulophia graminea, Geodorum densiflorum, Macodes petola, Malaxis koordersii dan Peristylus goodyeroides. Delapan jenis lainnya yaitu Bulbophyllum antenniferum, B. vaginatum, Eria bogoriensis, E. xanthocheila, Eria sp., Dendrobium cruminatum, Polystachya concreta, dan T. velutina tergolong anggrek epifit.

Jenis-jenis anggrek di Karimunjawa tidak tersebar merata di semua kawasan. Dua daerah yaitu Legon Lele dan Legon Goprak tercatat paling kaya akan jenis-jenis anggrek yaitu masing-masing terdapat 4 jenis. Kemudian diikuti oleh daerah Legon Moto dan P. Genting masing-masing dengan 3 jenis; dan Nyamplungan 2 jenis anggrek. Dua daerah lainnya yaitu P. Kembar (P.Kumbang dan P.Nyamuk) masing-masing hanya ditemukan 1 jenis anggrek. Hal yang cukup menarik adalah tidak ditemukannya jenis anggrek di pulau-pulau Bengkoang, Parang dan Sambangan. 
Tabel 1. Daftar jenis anggrek dari karimunjawa.

\begin{tabular}{|c|c|c|}
\hline Jenis & Persebaran di Karimunjawa & Persebaran di kawasan Malesia \\
\hline $\begin{array}{l}\text { Bulbophyllum } \\
\text { antenniferum }\end{array}$ & Legon Moto & Jawa, Kalimantan, Filipina, New Guinea. \\
\hline B. vaginatum & $\begin{array}{l}\text { Nyamplungan, Legon Lele, } \\
\text { Legon Moto, Kemloko }\end{array}$ & $\begin{array}{l}\text { Jawa, Sumatra, Kalimantan, Semenanjung } \\
\text { Malaya, Thailand. }\end{array}$ \\
\hline $\begin{array}{l}\text { Dendrobium } \\
\text { crumenatum }\end{array}$ & Pulau Genting & Asia Tenggara, China, India. \\
\hline Eria bogoriensis & Legon Lele, Legon Moto & Jawa, endemik \\
\hline E. xanthocheila & Kemloko & $\begin{array}{l}\text { Jawa, Sumatra, Kalimantan, Semenanjung } \\
\text { Malaya. }\end{array}$ \\
\hline $\begin{array}{l}\text { Eria sp.(sect. } \\
\text { Urostachya) }\end{array}$ & Legon Lele & \\
\hline Eulophia graminea & P. Nyamuk, P. Kumbang & $\begin{array}{l}\text { Asia Tenggara, Sri Lanka, India, China, } \\
\text { Okinawa. }\end{array}$ \\
\hline Geodorum densiflorum & $\begin{array}{l}\text { P. Kembar, P. Genting, Legon } \\
\text { Goprah }\end{array}$ & Asia Tenggara, Australia, India. \\
\hline Macodes petola & Nyamplungan & Jawa, Sumatra, Semenanjung Malaya, Filipina \\
\hline Malaxis koordersii & Legon Goprah & Jawa, Sulawesi \\
\hline $\begin{array}{l}\text { Peristylus } \\
\text { goodyeroides }\end{array}$ & P. Genting & Asia Tenggara, India, China, New Guinea \\
\hline Polystachya concreta & Legon Goprah & Seluruh daerah tropik \\
\hline Trichotosia velutina & Legon Lele & $\begin{array}{l}\text { Jawa, Sumatra, Kalimantan, New Guinea, } \\
\text { Thailand, Vietnam, Burma, Semenanjung } \\
\text { Malaya, P. Solomon }\end{array}$ \\
\hline
\end{tabular}

Adapun pertelaan jenis-jenis anggrek yang terdapat di Karimunjawa adalah sebagai berikut.

\section{Bulbophyllum antenniferum (Lindl.) Rchb.f.}

Bulbophyllum antenniferum (Lindl.) Rchb.f., Walp. Ann. 6: 250 (1861).

Anggrek epifit. Rimpang dipenuhi oleh akar. Umbi semu terdapat pada rimpang dengan jarak 5,5-7 cm, berukuran panjang $1,5-2,5 \mathrm{~cm}$, lebar $0,5-1 \mathrm{~cm}$. Daun dengan tangkai daun panjang $1 \mathrm{~cm}$, berbentuk lonjong sampai melanset, pada bagian ujungnya tumpul, melengkung ke bawah, panjang $13-13,5 \mathrm{~cm}$, lebar $2,5-3 \mathrm{~cm}$. Perbungaan mendukung 1 bunga, panjang $10 \mathrm{~cm}$. Daun kelopak bagian dorsal (atas) pada permukaan luar bagian pangkalnya berwarna kemerahan atau coklat serta bagian ujung kehijauan sedangkan pada permukaan dalam berwarna lebih pucat, panjang $6 \mathrm{~cm}$, lebar $2 \mathrm{~cm}$, daun kelopak lateral (samping) berwarna krem, panjang $4 \mathrm{~cm}$, lebar $1,25 \mathrm{~cm}$. Daun mahkota sangat kecil. Bibir melengkung berbentuk lidah, ujung tumpul, berwarna coklat dengan bintik merah muda serta berbulu. Buah bentuk kapsul, tangkai panjang $3,5-4 \mathrm{~cm}$, buah panjang $2-3 \mathrm{~cm}$, diameter $0,5-0,8 \mathrm{~cm}$, bibir bunga tetap melekat pada buah.

Persebaran: Comber ${ }^{2}$ menyebutkan jenis ini umum dijumpai di daerah pantai di Jawa Barat dan Jawa Timur. Namun koleksi di Herbarium Bogoriense hanya berasal dari Karimunjawa yaitu dikoleksi dari hutan sekunder di Legon Moto pada ketinggian $220 \mathrm{~m}$ dpl. Persebaran di tempat lain yaitu di Kalimantan, Filipina dan New Guinea. 


\section{Bulbophyllum vaginatum (Lindl.) Rchb.f.}

Bulbophyllum vaginatum (Lindl.) Rchb. f. In Walp. Ann. 6: 261 (1861).

Anggrek epifit, berimpang. Akar hanya terdapat di bagian yang berumbi semu. Umbi semu panjang $2 \mathrm{~cm}$, diameter 1 $\mathrm{cm}$, jarak antar umbi semu $5 \mathrm{~cm}$. Daun lonjong, panjang $12 \mathrm{~cm}$, lebar $2,5 \mathrm{~cm}$, tebal, permukaan atas cembung, tulang daun tertekan, ujung tumpul dan berlobus. Perbungaan berbentuk payung semu yang terdiri dari $12-15$ bunga, berwarna kuning muda. Daun kelopak atas berbentuk seperti peci serta bagian tepinya berbulu, panjang 8 $\mathrm{mm}$; daun kelopak samping panjang $6,5 \mathrm{~cm}$, di bagian pangkalnya bersatu, bagian ujung berbetuk benang. Daun mahkota berbentuk jorong, pada bagian tepinya berbulu, panjang $2,5 \mathrm{~cm}$. Bibir berbentuk lidah, panjang $2 \mathrm{~mm}$, berwarna kuning muda.

Persebaran: Menurut Comber ${ }^{2}$ jenis ini hanya ditemukan di daerah trenggalek. Namun koleksi di Herbarium Bogoriense di koleksi dari Banjar, Purwokerto, Kalimantan Timur dan Sumatra. Persebaran tempat lain adalah di Semenanjung Malaya dan Thailand. Di Karimunjawa ditemukan di Nyamplungan, Legon Lele, Legon Moto, Legon Goprah dan Kemloko.

\section{Dendrobium crumenatum Sw.}

Dendrobium crumenatum Sw., Schrad., Neues Journ. 2: 237 (1799)

Anggrek epifit, bergerombol. Batang di dekat pangkal membengkak membentuk umbi semu, beruas-ruas. Daun terdapat di ujung batang, tersusun berseling, berbentuk bundar telur. Bunga terdapat pada bagian ujung batang yang tidak berdaun, berwarna putih. Jenis ini dikenal dengan nama daerah anggrek merpati

Persebaran: Di Karimunjawa hanya di temukan di P. Genting. Namun jenis ini tersebar luas di India, China dan seluruh kawasan Asia Tenggara.

\section{Eria bogoriensis J.J.Sm.}

Eria bogoriensis J.J.Sm., Enum. Orch. Sumatra: 252 (1933).

Anggrek epifit Batang bergerombol, pada bagian ujung melebar, panjang $9-14 \mathrm{~cm}$, lebar bagian pangkal $0,2-0,3 \mathrm{~cm}$, bagian ujung 0,5 $\mathrm{cm}$. Daun terdapat di ujung batang berjumlah $3-4$, bentuk melanset, panjang $10-14 \mathrm{~cm}$, lebar $1-1,5 \mathrm{~cm}$, ujung lancip. Perbungaan muncul dari ujung batang, tegak, panjang 5-9 $\mathrm{cm}$, mendukung banyak bunga.

Persebaran: Di Karimunjawa di koleksi dari daerah Legon Lele dan Legon Moto, pada ketinggian 0-360 m dpl. Jenis ini endemik di Jawa, tersebar di seluruh Jawa.

\section{Eria xanthocheila Ridl.}

Eria xanthocheila Ridl. In Mat. Fl. Mal. Penins. 1: 102 (1907).

Anggrek epifit, berimpang. Batang terdapat pada rimpang dengan jarak antar batang 0,5-1 cm, batang bagian pangkal membengkak membentukumbi semu, panjang $18-30 \mathrm{~cm}$, beruas-ruas, jarak antar ruas 2,5 $-3 \mathrm{~cm}$, batang diselubungi oleh pelepah yang mudah luruh. Daun terdapat di ujung batang, berjumlah 3 buah, bundar telur, panjang 15-25 $\mathrm{cm}$, lebar 2,5-3 cm, ujung lancip. Perbungaan muncul pada batang, terletak di bawah daun.

Persebaran: Di Karimunjawa di koleksi dari hutan sekunder di daerah Kemloko pada ketinggian $40 \mathrm{~m}$ dpl. Persebaran tempat lain adalah di Sumatra, Kalimantan dan Semenanjung Malaya.

\section{Eria sp.}

Jenis ini seperti E. bogoriensis hanya daun lebih lebar, posisi perbungaan menggantung. Persebaran: Jenis ini ditemukan di Legon Lele.

\section{Eulophia graminea Lindl.}

Eulophia graminea, Gen. Spec. Orch. Pl.: 182 (1833). 
Anggrek tanah. Umbi semu berdiameter sekitar $2 \mathrm{~cm}$. Daun dengan pelepah tersusun saling menutup, panjang daun $9-20$ cm, lebar 0,5 - 1,5 cm, luncip, daun yang terbawah paling kecil. Perbungaan muncul pada ketiak daun, panjang $26-70 \mathrm{~cm}$, bercabang-cabang. Bunga masing-masing dilindungi oleh daun pelindung bunga yang tidak mudah luruh, berwarna coklat tua. Daun kelopak atas panjang $1 \mathrm{~cm}$, lebar 0,2 cm, lancip. Daun kelopak samping panjang $1 \mathrm{~cm}$, lebar 0,2 cm, luncip. Kaki tugu panjang 0,2 $0,3 \mathrm{~cm}$, ujungnya membulat. Buah berbentuk kapsul, panjang $2 \mathrm{~cm}$, lebar $1 \mathrm{~cm}$.

Persebaran: Di Karimunjawa di koleksi dari daerah P. Nyamuk dan P. Kumbang pada ketinggian $10 \mathrm{~m}$ dpl. Jenis ini tersebar di Sri Lanka, India, Asia Tenggara, China dan Okinawa.

8. Geodorum densiflorum (Lamark) Schltr.

Geodorum densiflorum (Lamark) Schltr. in Fedde. Repert. Beih. 4: 259 (1919).

Anggrektanah. Umbi semu berdiameter sekitar $2 \mathrm{~cm}$. Daun $2-3$, diselubungi oleh 2 pelepah daun yang berbentuk tabung, pelepah daun bagian ujung bentuknya menyerupai daunnya. Perbungaan muncul dari umbi semu, panjang $40-50 \mathrm{~cm}$. Bunga tidak mengalami resupinasi. Buah berbentuk kapsul, panjang $2-2,5 \mathrm{~cm}$, lebar $1-1,5 \mathrm{~cm}$.

Persebaran: Di Karimunjawa di koleksi dari daerah perladangan di Legon Goprak pada ketinggian $55 \mathrm{~m}$ dpl. Juga di hutan pantai Pulau Kembar. Jenis ini pertama kali ditemukan di India, kemudian meluas sampai Asia Tenggara dan Australia.

\section{Macodes petola (BI.) Lindl.}

Macodes petola (BI.) Lindl., Gen. et Spec. Orch.: 497 (1840).

Anggrek tanah, berimpang. Batang panjang $3 \mathrm{~cm}$. Daun $2-6$, bundar sampai bundar telur, panjang 3,5-7 cm, lebar 2-4,5 cm, luncip, urat daun jelas terlihat menyerupai tulisan sehingga oleh orang Sunda anggrek ini disebut ki aksara. Perbungaan muncul dari ujung batang, panjang $12-19 \mathrm{~cm}$, bunga hanya terdapat di dekat ujung.

Persebaran: Di Karimunjawa di koleksi dari Nyamplungan. Selain di Jawa juga tersebar di Sumatra, Semenanjung Malaya dan Filipina

10. Malaxis koordersii (J.J.Sm.) Bakh.f.

Malaxis koordersii (J.J.Sm.) Bakh.f. in Blumea 12: 68 (1963).

Anggrek tanah. Batang panjang 11 - $13 \mathrm{~cm}$, berwarna hijau. Daun berjumlah 3 - 5 helai, melanset, panjang $13-15$ $\mathrm{cm}$, lebar $4-4,5 \mathrm{~cm}$, bagian pangkal tidak simetris, bagian ujung lancip, bagian tepi sedikit bergelombang. Perbungaan muncul dari ujung batang, panjang 15-43 $\mathrm{cm}$, mendukung beberapa bunga. Bunga berwarna hijau muda, apabila sudah tua berubah menjadi kekuningan.

Persebaran: Di Karimunjawa di koleksi dari Legon Goprak. Menurut Comber ${ }^{2)}$ jenis ini endemik di Jawa, tetapi penulis menemukan jenis ini di Pulau Wawonii ${ }^{8)}$.

\section{Peristylus goodyeroides (D.Don) Lindl.}

Peristylus goodyeroides (D.Don) Lindl., Gen. Spec. Orch. PI.: 299(1835)

Anggrek tanah, berumbi. Umbi semu panjang 1,5 - 2,5 cm, lebar 0,8 $-1 \mathrm{~cm}$. Batang di selubungi oleh pelepah yang berbentuk tabung, panjang $15-40 \mathrm{~cm}$, daun terdapat di batang bagian atas, batang bagian bawah di selubungi pelepah. Daun tersusun berhadapan, tidak bertangkai, bundar telur sampai lonjong, panjang 5-15 cm, lebar 2,5 $-5 \mathrm{~cm}$, luncip. Perbungaan muncul dari ujung batang, panjang $15-45 \mathrm{~cm}$, bunga tersusun rapat di bagian tengah sampai ke ujung perbungaan, gagang perbungaan panjang $8-28 \mathrm{~cm}$, dilindungi oleh daun pelindung steril, rakis panjang $7-17 \mathrm{~cm}$, tiap bunga dilindungi oleh daun pelindung. 
Persebaran: Di Karimunjawa di koleksi dari hutan sekunder Pulau genting pada ketinggian $40 \mathrm{~m}$ dpl. Jenis ini umum di jumpai di Jawa, tersebar di Asia Tenggara, juga terdapat di India, China, New Guinea.

12. Polystachya concreta (Jacq.) Garay \& Sweet.

Polystachya concreta (Jacq.) Garay \& Sweet in Orchideologia 9 (3): 206 (1974).

Anggrek epifit, berumbi semu. Akar pipih tersusun rapat. Daun berpelepah, melanset, lancip, panjang $25 \mathrm{~cm}$, lebar 5 $\mathrm{cm}$. Perbungaan muncul dari ujung umbi semu, bercabang-cabang. Bunga tidak mengalami resupinasi sehingga kedudukan bibirnya di atas, berwarna kuning atau hijau pucat.

Persebaran: Di Karimunjawa di koleksi dari Legon Goprak. Sedangkan persebaran tempat lain yaitu di seluruh daerah tropik.

13. Trichotosia velutina (Lodd ex. Lindl.) Kraenzl.

Trichotosia velutina (Lodd.ex Lindl.) Kraenzl. In Engl. Pflanzenr. Orch. Mon. Dendr. 2: 140 (1911).

Anggrek epifit, bergerombol. Batang panjang $50-75 \mathrm{~cm}$, lebar $0,5 \mathrm{~cm}$, diselubungi oleh pelepah daun berbentuk tabung yang melekat erat pada batang, panjang pelepah $3 \mathrm{~cm}$, berbulu. Daun tersusun berseling, berbentuk bundar telur, panjang 7,5 - 8,5 cm, lebar 1,5 - 2 cm, lancip, berbulu. Perbungaan muncul pada ruas batang yang berhadapan dengan letak daun, panjang 1 $\mathrm{cm}$, berbulu coklat, mendukung dua bunga, tiap bunga dilindungi oleh daun pelindung yang tidak mudah luruh. Buah berbetuk kapsul, panjang 1,5 cm.

Persebaran: Di Karimunjawa ditemukan di Legon Lele. Persebaran tempat lain di Sumatra, Kalimantan, New Guinea, Thailand, Vietnam, Burma, Semenanjung Malaya dan P. Solomon.

\section{KESIMPULAN}

Dari hasil penelitian ini telah terdokumentasi sebanyak 13 jenis anggrek Karimunjawa. Satu jenis diantaranya yaitu Eria bogoriensis tercatat sebagai jenis anggrek endemik di Jawa, dan 1 jenis lainnya yaitu Eria sp. masih perlu penelitian lebih lanjut untuk memastikan jenis dan statusnya.

\section{DAFTAR PUSTAKA}

1. Dressler, R. L., 1981. The Orchid: Natural History and Classification. Harvad University Press Cambridge, Massachusetts and London, England.

2. Comber, J. B., 1990. Orchid of Java. Bentham - Moxon Trust. Royal Botanic Gardens, Kew.

3. Backer, C.A. \& Bakhuizen v/d Brinks, 1968. Flora of Java vol. III. Wolters. Noordhoff N.V. - Groningen - The Netherlands.

4. Puspitaningtyas, D.M., S. Mursidawati, Sutrisno, J. Asikin, 2003. Anggrek Alam di Kawasan Konservasi Pulau Jawa. Lembaga Ilmu Pengetahuan Indonesia. Pusat Konservasi Tumbuhan Kebun Raya Bogor.

5. Schmidt, F.H. and J.H.A. Ferguson, 1951. Rainfaall types based on wet and dry period ratios for Indonesia with western New Guinea. Djawatan Meteorologi dan Geofisika Jakarta. No. 42.

6. Anonim, 2003. Statistik Balai Taman Nasional Karimunjawa Tahun 2002. Departemen Kehutanan Direktorat Jenderal Perlindungan Hutan dan Konservasi Alam. Balai Taman Nasional Karimunjawa. Semarang.

7. Balgooy, M. J. J. van, 1987. Collecting in Vogel: Manual of Herbarium Taxonomy Theory and Practice: $14-19$.

8. Sulistiarini, D., S. Sunarti dan H. Wiriadinata, 2007. Rekaman Baru Anggrek dari Pulau Wawonii. Biodiversitas Vol. 8, No. 2: 83 - 87. 